\title{
Women experienced communion, strength, and understanding of their partners' feelings by having their partners present at the birth of their babies
}

\author{
Bondas-Salonen T. How women experience the presence of their partners at the births of their babies. Qual Health Res 1998 \\ Nov;8:784-800.
}

\section{Question}

How do women experience the presence of their partners at the birth of their babies?

\section{Design}

Phenomenology.

\section{Setting}

Healthcare centres, hospitals, and women's homes in Finland.

\section{Patients}

40 Finnish women who had given birth to 1-6 children. Women had different educational backgrounds, ages, types of housing, and occupations. A woman's partner was defined as the man who was present at childbirth and the alleged father of the child. 9 women were followed up for 2.5 years.

\section{Methods}

Data were obtained before, during, and after delivery by observations of lived events and through 80 interviews. Interviews lasted 20-75 minutes, used open ended questions, and addressed the women's experiences of health and care during the pregnancy and delivery, and after childbirth. Women were encouraged to talk freely about their childbirth and life experiences. Data were recorded, transcribed, and analysed for categories and emergent themes according to Colaizzi's methods. The findings were compared with Eriksson's theory of caritative caring. Results were validated by follow up interviews, review of the transcripts by the women, and discussions with experienced midwives and public health nurses.

\section{Main findings}

3 major categories were found. The first category, communion, included themes of expressing concern and showing love, sharing worries and joy, participating in the preparation for childbirth, the importance of the partner's presence, the partner's ability to care for the woman and the baby in the best possible way, participating in different ways, the presence of the partner as different from that of other support people or healthcare staff, and creating a family together. The second category, strength, referred to the partner's presence as having alleviated loneliness, pain, fear, and anxiety during the delivery and providing care and strength to endure the suffering and share the joy of birth. The third category, two worlds, represented the women's thoughts that their partners needed care as well, lacked a place in the healthcare culture, had different views than their own or others, and were given another view of life through the childbirth experience.

\section{Conclusions}

Women felt that the presence of their partners at the birth of their babies was meaningful and important for establishing communion and gaining strength during the childbirth experience. Women understood that their partners experienced the childbirth differently than themselves or others.

Sources of funding: Stiftelsens för Åbo Akademis forkningsinstitut; Åbo Akademi University; Sjuksköterskeföreningen $i$ Finland $r f$

For correspondence: T Bondas-Salonen, Department of Caring Science, Åbo Akademi University, Vasa, Finland. Fax +35863247503 .

\section{Commentary}

This qualitative study by Bondas-Salonen explored women's feelings about their partner's presence during their childbirth experience.

The study extends beyond similar research by using a creative methodological approach. A diverse sample of 40 Finnish women was used and data were collected by interviews and observations over time. This approach helped to identify the essence of the phenomenon of partner presence as perceived by these women during pregnancy, birth, the period immediately after birth, and up to 2 years after giving birth.

The use of Colaizzi's phenomenological method of data collection and analysis, ${ }^{1}$ Eriksson's caritative caring theory for interpretation of findings, ${ }^{2}$ and review of interviews and observations by participants, midwives, and public health nurses strengthen the study and provide relevant information for evaluating current maternity care services in Finland. Partner presence provided a "safe harbour" for these women, who perceived an unresponsive system of care that failed to offer desired family education, consistent information, health promotion, and accessible and individualised care to each member of the pregnant couple. The findings showed that women valued the support of their partner during pregnancy, after birth, and long after childbirth. This supports the concept of the human need for receiving and experiencing hope and faith, which are components of Eriksson's caritative theory. The findings also support the view that professional nursing roles must incorporate interdependent humanistic and technological care approaches that respond to the unique needs and perceptions of pregnant couples so that these couples may establish a strong foundation for their future families.

Carolyn Spence Cagle, RNC, PhD Associate Professor Harris College of Nursing Texas Christian University Fort Worth, Texas, USA

1 Colaizzi PP. Psychological research as a phenomenologist views it. In: Valle RS, King M, editors. Existential-phenomenological alternatives for psychology. New York: Oxford University Press, 1978;48-71.

2 Eriksson K. Scand J Caring Sci 1992;6:119-23. 